\title{
Letters
}

\section{Health in Africa}

Time to wake up to cancer's toll

EDITOR-As exemplified by your theme issue on Africa of 1 October, cancer has remained comparatively neglected in Africa although increasingly prevalent: $70 \%$ of people with cancer live in the economically developing world, where by 2020 the annual death toll is predicted to reach 20 million. ${ }^{1}$

In sub-Saharan Africa measures to prevent cancer emphasised in the developed world-such as smoking cessation and screening-are not nationally adopted. One third of African cancers are preventable, but the influence of tobacco companies with mass media advertising and high crop payments is real. Traditional cancers, such as gastric and hepatocellular carcinoma, and newer cancers, such as lung cancer, breast cancer, and AIDS related Kaposi's sarcoma, are increasing in incidence. ${ }^{23}$

Patients' expectations for oncological treatment are low in Africa. Lack of money, or a concern not to place their family in debt, prevents many from seeking medical help. ${ }^{4}$ Lack of awareness of predisposing factors, warning symptoms or signs of cancer, or treatment options mean that patients present late. Cost and difficulty of travel over rough terrain also

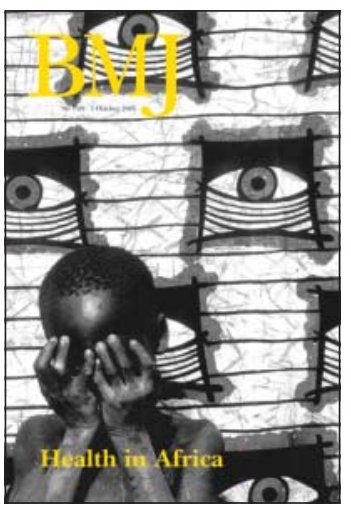

Competing interests: None declared.

1 Murray JL, Lopez AD. The global burden of disease. Boston: Harvard School of Public Health, 1996.

2 Morris K. Cancer? In Africa? Lancet Oncol 2004;4(1):5-6

3 Walker AR, Adam FI, Walker BF. Breast cancer in black African women: a changing situation. J R Soc Health 2004; 124:81-5

4 Murray SA, Grant E, Grant A, Kendall M. Dying from cancer in developed and developing countries: lessons from two qualitative interview studies of patients and their carers. BMJ 2003;326:368-71.

5 World Health Organization. National cancer control programs. Geneva: WHO, 2005.

British mental health trust twins with psychiatric service in Sierra Leone

EDITOR-Barnet, Enfield, and Haringey Mental Health NHS Trust has formally twinned with mental health services in Sierra Leone. ${ }^{1}$ This small project, currently funded by UNISON trade union, aims to provide regular, annual, in-service training programmes for staff at Kissy Mental Hospital, Freetown, and other health workers and trainees in Sierra Leone. The programme is formally supported by the British High Commission in Freetown, and the first delegationof trust staff drawn from various disciplines and some originating from Sierra Leone discourage service use. After diagnosis patients may tend to look for peace of mind and spiritual comfort rather than a physical cure

In Africa disease modifying cancer treatment and basic control of symptoms are largely absent. Even when analgesia is available, patients with cancer may experience severe and inadequately managed pain, as health professionals underprescribe strong analgesics, fearing drug dependency. ${ }^{5}$

Individual sub-Saharan countries cannot tackle the challenges of cancer in isolation. A new, cooperative approach and research base are being advocated for preventing, treating, and palliating cancer to bridge the gap between developed and developing nations. ${ }^{5}$

Scott A Murray reader

scott.murray@ed.ac.uk

Elizabeth Grant research fellow

Primary Palliative Care Research Group, Division of Community Health Sciences; General Practice,

University of Edinburgh, Edinburgh EH8 9DX

Faith Mwangi-Powell executive director

African Palliative Care Association (APCA),

PO Box 72518, Kampala, Uganda and other parts of west Africa will travel to Freetown next month.

We hope to learn from this programme as much as our colleagues in Sierra Leone hope to learn from us. The population in parts of the trust has a high proportion of refugees affected by war in their country of origin, including those of west, central, and the Horn of Africa. And we hope to help our colleagues in Sierra Leone develop sustainable mental rather than depending on the short term interventions of non-governmental organisations.

Shaun Collins assistant director

Child and Adolescent Mental Health, Barnet, Enfield, and Haringey Mental Health NHS Trust shaun.collins@beh-mht.nhs.uk

Competing interests: None declared.

1 Asare J, Jones L. Tackling mental health in Sierra Leone. BMJ 2005;331:720. (1 October.) health services provided by themselves,
In Taiwan, taking action on road safety made a difference

EDITOR-Ten years ago Taiwan was a developing country like many in Africa with a high mortality due to road traffic injuries. Mortality due to road crashes was stable at 7500 people a year from 1990 to 1995 . It dropped from about 7500 in 1995 to 4300 in 2003-a 42.7\% decrease in nine years. Various reasons led to this result, the most important factor having been vigorous government policies and campaigns relating to traffic safety. These include:

- 1994 Enforcement of helmet use in Taipei City

- 1997 Implementation of helmet law

- 1998 Implementation of an emergency medical system

- 1999 Enforcement of regulations on wearing seat belts and not using cell phones while driving and strict prohibition of drinking and driving

- 2001 Campaign to use safety seats for children.

An active policy taken by the government was essential in improving road safety. The efforts of people from many sectors and disciplines, including public health professionals, healthcare providers, road and motor vehicle engineers, law enforcement officials, and educators, are crucial.

Min-Huei Hsu consultant neurosurgeon

Taipei Municipal Wanfang Hospital, No 111, Sec 3, Shinglung Road, Taipei City, Taiwan 116 701056@tmu.edu.tw

Yu-Chuan Li chief, Graduate Institute of Medical Informatics

Wen-Ta Chiu vice president

Taipei Medical University, Taipei, Taiwan

Competing interests: None declared.

1 Khayesi M, Peden M. Road safety in Africa. BMJ 2005; 331:710-1. (1 October.)

It's time for good guidelines on health financing practice

EDITOR-The intervention of global organisations in the public health systems of African countries ${ }^{12}$ is a form of research involving humans and should be subject to the Declaration of Helsinki and good clinical practice guidelines. ${ }^{34}$

In structural reforms, global organisations (the investigators) work to convince the governments of countries (legal representatives of the study subjects) to take part in health financing reforms (or policy experiments, the new "medical" procedure). Since the health consequences of the interventions are largely unknown and the outcomes are used as a basis of an evidence base, these policy interventions are a form of experi- 
mentation (medical research) and should be subject to the same scrutiny as other studies. But they fall far short.

The Declaration of Helsinki is infringed from the main consideration being related to financial outcomes rather than the wellbeing of the human subjects (reduced government budget deficit is a poor surrogate marker of the real health outcomes), to the conflicts of interest arising from the dependency relations between the global institutions and the national governments such that the volunteers give "consent under duress" in the light of the financial inducements to participate. Also, when governments lack suitable expertise, these volunteers "cannot give or refuse consent for themselves."

Other failings are evident in the lack of an independent ethical review and the equivalent of an independent data monitoring and safety committee. Furthermore, a compensation mechanism should exist for subjects who find themselves worse off as a result of their participation in the experiment. Yet the organisations recommending or even imposing the reforms take no financial or moral liability for any unfavourable outcomes, rather leaving it to the governments to take care of the consequences.

Douglas E Ball associate professor

Department of Pharmacy Practice, Faculty of

Pharmacy, Kuwait University, Kuwait

dball@hsc.edu.kw

Competing interests: None declared.

1 James C, Morris SS, Keith R, Taylor A. Impact on child mortality of removing user fees: simulation model. $B M J$ 2005;331:747-9. (1 October.)

2 Gilson L, McIntyre D. Removing user fees for primary care in Africa: the need for careful action. BMJ 2005;331:762-5 (1 October.)

3 World Medical Association. Declaration of Helsinki. 52nd WMA General Assembly, Edinburgh, 2000.

4 Council for International Organizations of Medical Sciences. International ethical guidelines for biomedical research involving human subjects. Geneva: CIOMS, 2002.

\section{Let's learn from the success stories from other poor countries...}

EDITOR-Why is it that donor agencies and policy advisers continue to ignore success stories from poor countries such as Sri Lanka? ${ }^{1}$ Together with Cuba, Costa Rica, and Kerala in India, Sri Lanka's achievements have been exemplary. Much has been written about these models, but rarely are there attempts to replicate them in developing countries. ${ }^{2}$ Are they out of date or are they too alien to even consider?

Saroj Jayasinghe associate professor

Faculty of Medicine, University of Colombo,

Sri Lanka

sarojoffice@yahoo.com

Competing interests: None declared.

Gilson L, McIntyre D. Removing user fees for primary care in Africa: the need for careful action. BMJ 2005;331:762-5. (1 October.)

2 Bhutta Z, Nundy S, Abbasi K. Is there hope for South Asia? BMJ 2004:328:777-9.

\section{... and get back to basics}

EDIToR-More of the same will not ease Africa's health crisis. ${ }^{1}$ As an African with training and work experience in interna- tional health, I think that we need to go back to basics.

Reducing poverty may be a starting point. However, when it comes to rational use of the meagre monetary resources in sub-Saharan Africa, inefficient management of resources and corruption become serious stumbling blocks. Granted that corruption is almost worldwide, its rampant nature in Africa causes problems with monies available, received, and disbursed by the appropriate agencies in some countries. ${ }^{2}$

As to efficient use of meagre resources, some countries outside Africa (for example, Jamaica) that are in the same developmental bracket as some African countries do far better with less. ${ }^{3}$ The general determinants of the health of populations show that an efficient, robust, and performing health services organisation is basic to the health of nations. ${ }^{4}$ Human capacity building, as the mainstay of all organisations, especially for health service delivery, research, etc, has suffered in most African countries, more so in recent times from net migration from sub-Saharan Africa to the developed world (or much wealthier developing countries). Sub-Saharan African governments and their developed counterparts need to work hard together to find pragmatic solutions to the brain drain problem.

The health crisis in Africa will continue to be more of the same, unless we seriously tackle the underlying issues driving the crisis.

Albert M E Coleman associate specialist psychiatrist Greenacres Community Mental Health Trust, Worthing and Southlands Hospitals NHS Trust, Worthing, West Sussex BN11 2DH albert.coleman@gmail.com

\section{Competing interests: None declared.}

1 Sanders DM, Todd C, Chopra M. Confronting Africa's health crisis: more of the same will not be enough. $B M J$ 2005;331:755-8. (1 October.)

Eaton L. Global fund toughens stance against corruption. BMJ 2005;331:718. (1 October.)

3 Evans DB, Tandon A, Murray CJL, Lauer JA. Comparative efficiency of national health systems: cross national econometric analysis. BMJ 2001;323:307-10. (11 August.)

Blum HL. Planning for health. Generics for the eighties. Washington, DC: Human Sciences Press, 1981:2-9.

5 Johnson J. Stopping Africa's medical brain drain. BMJ 2005;331:2-3 (2 July.)

\section{Medical brain drain is a consequence of bad policy}

EDITOR-The medical brain drain is not new. ${ }^{1}$ During my undergraduate medical education in Africa, most of our lecturers had at some stage trained abroad. Our impression was that standards were better in Europe and America. Attached to this was a clear message that if you wanted to be the best, experience abroad was crucial. Experience in Europe or America conferred a special status on doctors as most government funded hospitals relied on such doctors to draw on their new experiences to improve local standards.

Apart from the obvious training benefits, the opportunity to earn a good income for a limited period was too good for many to pass up. To think that the brain drain happens purely for financial and economic benefits is, however, an over-simplification. The key is the inability to maintain a "migration equilibrium."

In the past, doctors who left Africa returned proud of their experience and newly found status, more fulfilled, and keen to pass on their knowledge. They were happy to work in less well funded but nevertheless safe environments.

Years of underinvestment in the health sector, poor management of resources, and government malaise have eroded the previously high standards in many institutions. Doctors returning quickly find that the working environment is not safe, and word spreads quickly.

The prospect of moving to a better environment and living a more fulfilled life transcends professions or origin. The key to retention in Africa is to make people feel valued and create an environment where doctors can feel fulfilled in doing what they do best-saving lives.

Gbola O Sangosanya specialist registrar Chelsea and Westminster Hospital, London SW10 9NH gosango2003@yahoo.co.uk

Competing interests: GOS was trained in Africa and is currently working in the UK.

Twisselmann B. Africa's medical brain drain. BMJ 2005; 331:780-1. (1 October.)

\section{Insulin pumps: more consultation was needed}

EDITOR-Colquitt et al recently published a health technology assessment on the clinical and cost effectiveness of continuous subcutaneous insulin infusion for diabetes for the National Institute for Health and Clinical Excellence (NICE). ${ }^{1}$ Believing that some important issues needed to be communicated with other readers, we contacted the NHS Health Technology Assessment Programme and were informed that its journal does not offer the opportunity to respond to previous appraisals in forthcoming publications (although the programme's website offers a forum for discussion, at www.ncchta.org/correspond/).

Given the potential impact of such publications in the United Kingdom and beyond, this approach caused us concern, as we believe that the website discussion would reach only a limited audience. We here outline certain shortcomings of the assessment by Colquitt et al.

Colquitt et al based their findings on a literature review made before August 2002 (published in October 2004), at which time no published cost effectiveness analyses on continuous subcutaneous insulin infusion $v$ multiple daily injections of insulin existed. The authors said that they were unable to identify health outcomes that can be quantified for the purposes of cost effectiveness analysis, particularly in terms of translating observed benefits for glycaemic control into costs per quality adjusted life year (QALY) gained. However, publications on at least four health economic models that are able to project the long term change in risk of 
complications dependent on concentrations of glycated haemoglobin, and thereby calculate clinical and cost outcomes, were available at that time..$^{2-5}$ Since the completion of the review, at least five other peer reviewed diabetes models have been published that can project cost effectiveness on the basis of changes in glycated haemoglobin, and two further studies have actually examined the cost effectiveness of implementing continuous subcutaneous insulin infusion $v$ multiple daily injections of insulin treatment in the UK, both reporting attractive incremental cost effectiveness ratios (see longer version of this letter).

Colquitt et al did not seek further consultation from competent health economic modelling groups with experience in diabetes before publishing their report. If they had they would have been unlikely to conclude that they had not found a satisfactory method, in the time available, of converting observed benefits into a cost per QALY. A method has been available for some time and, in the years between completion of the review and its publication, several transparent, validated, and generally well accepted computer simulation models of diabetes have been described in the medical press (see longer version of this letter).

Andrew J Palmer director, medical research ap@thecenter.ch

Daniel M D Tucker health economist

Joshua A Ray health economist

William J Valentine health economist

CORE-Centre for Outcomes Research,

Buendtenmattstrasse 40, 4102 Binningen,

Switzerland

Craig Currie honorary research fellow in diabetes, endocrinology, and metabolism

Department of Medicine, Cardiff University, University Hospital of Wales, Cardiff CF14 4UJ

Phil McEwan director

School of Mathematics, Cardiff University, Cardiff CF14 4UJ

Michael Brändle director

Division of Endocrinology and Diabetes,

Department of Internal Medicine, Kantonsspital St Gallen, Switzerland

Competing interests: AJP, DMDT, JAR, and WJV are all employees of CORE. CORE has received an unrestricted grant from Medtronic to perform an analysis evaluating the cost effectiveness of subcutaneous pumps.

1 Colquitt JL, Green C, Sidhu MK, Hartwell D, Waugh N. Clinical and cost-effectiveness of continuous subcutaneous insulin infusion for diabetes. Health Technol Assess 2004; 8(43):iii, 1-iiil71.

2 Palmer AJ, Weiss C, Sendi PP, Neeser K, Brandt A, Singh G, et al. The cost-effectiveness of different management strategies for type I diabetes: a Swiss perspective. Diabetologia 2000;43:13-26.

3 Eastman RC, Javitt JC, Herman WH, Dasbach EJ, CopleyMerriman C, Maier W et al. Model of complications of NIDDM. II. Analysis of the health benefits and costeffectiveness of treating NIDDM with the goal of effectiveness of treating NIDDM with the goal of normoglycemia

4 Brown JB, Russell A, Chan W, Pedula K, Aickin M. The global diabetes model: user friendly version 3.0. Diabetes Re Clin Pract 2000;50(suppl 3):S15-46.

5 Bagust A, Hopkinson PK, Maier W, Currie CJ. An economic model of the long-term health care burden of type II diabetes. Diabetologia 2001;44:2140-2155.

A longer version of this letter including all references is available at http://bmj.com/cgi/ eletters/324/7339/705\#118511

\section{Data need to be accurate when screening for depression in teenagers}

EDITOR-With reference to Lenzer's news article, ${ }^{1}$ one of the problems with promotion of universal mental health screening of children-and a good reason for many people's suspicions of another agenda-is the often inflated numbers cited. For example, the TeenScreen website notes that one in 10 American children and adolescents experience mental illness and impairment, but only one in five receives treatment. ${ }^{2}$ The source cited is a US Surgeon General's report from 2001-in support of a "National Action Agenda on Children's Mental Health."

Yet the US Centers for Disease Control (CDC) reports that in 2001-3, 5\% of American children aged 4-17 had emotional or behavioural difficulties, based on over 10000 national health interview surveys. The CDC also reports that these difficulties had an impact on functioning in $80 \%$-in other words, $4 \%$ of the total, substantially lower than the $10 \%$ cited by TeenScreen and perhaps not the "public crisis in mental health for children and adolescents" that the Surgeon General's report claimed. ${ }^{34}$

The CDC also reports that in 2003, 65\% of children aged 4-17 with emotional or behavioural difficulties received some type of mental health service for their problem, with $45 \%$ receiving help from a mental health professional and 40\% from a general physician. $^{5}$ Again, this is substantially different from the $20 \%$ treatment rate cited by TeenScreen. $^{2}$

Joan McClusky medical writer
New York, NY 10003, USA

jmcclusky@medimedia.com

\section{Competing interests: None declared.}

1 Lenzer J. US teenager's parents sue school over depression screening test. BMJ 2005;331:714. (1 October.)

2 Columbia University TeenScreen Program. Setting the record straight about TeenScreen. www.teenscreen.org/ $\mathrm{cms} /$ content/view/107/139/(accessed 6 Oct 2005).

3 Office of the Surgeon General. Surgeon general releases a national action agenda on children's mental health www.hhs.gov/surgeongeneral/news/pressreleases pressreleasechildren.htm (accessed 6 Oct 2005).

4 Centers for Disease Control and Prevention. U.S. children with emotional and behavioral difficulties: data from the 2001, 2002, and 2003 national health interview surveys. www.cdc.gov/nchs/data/ad/ad360.pdf (accessed 6 Oct 2005).

5 Centers for Disease Control and Prevention. QuickStats: percentage of children aged 4-17 years with emotional or behavioral difficulties* who used mental health services, by type of service-United States, 2003. www.cdc sov/mmwr/ type of service-United States, 2003. www.cdc.gov/ $\mathrm{mmwr} /$ 2005).

\section{Europe in transition}

Biomedical research from eastern Europe may be under-represented

EDITOR-The unique database of ISI (Institute of Scientific Information) has well known limitations in assessing biomedical research. ${ }^{1}$ The most important one is that its content mainly reflects the mostly English language pool of the "international journals." Some European non-English speaking countries, and especially east European countries, have a strong tradition of publishing in their native languages. This pool of publications is not closely connected to the one reflected in the ISI database.

The "quality" of research products published in local journals may be disputed, but the quantity or research input of east European countries is underestimated in the study by Soteriades and Falagas.'

Vasiliy Vlassov director

Russian Branch of the Nordic Cochrane Centre, Cochrane Collaboration, PO Box 13, Moscow 109451, Russia

vlassov@cochrane.ru

Competing interests: None declared

1 Soteriades ES, Falagas ME. Comparison of amount of biomedical research originating from the European Union and the United States. BMJ 2005;331:192-4. (23 July.)

\section{Dietary fat is not the villain}

EDITOR-Zatonski and Willett claim that a decrease of saturated fat and an increase of polyunsaturated fat consumption explain the decrease of coronary heart disease in Poland. ${ }^{1}$ However, ecological data are prone to bias because they are rarely, if ever, adjusted for confounders. In this case they are even contradicted by similar studies in the past. In a review including 103 time periods in 35 countries, I found that in 30 time periods an increased intake of saturated fat was followed by increased coronary mortality, but after 29 other periods with increased saturated fat consumption heart mortality was unchanged in six and decreased in $23 .^{2}$

Zatonski's and Willett's statement that their finding is supported by epidemiological and clinical evidence is not true either. In a review of all cohort and case-control studies, heart patients had eaten more saturated fat than had healthy controls in three cohorts, but in one cohort they had eaten less, and in 22 cohorts and in six case-control studies no difference was found. ${ }^{2}$ No cohort study or case-control study has found that coronary patients have eaten fewer polyunsaturated fats either; on the contrary, three cohort studies found that they had eaten more than the healthy controls, and in 29 studies no difference was found. ${ }^{2}$

The absence of an association between fat intake and coronary disease was recently confirmed in a large Swedish population study. ${ }^{3}$ No association has been found either between intake of dietary fats and degree of atherosclerosis at necrotopsy. ${ }^{2}$ Most importantly, two meta-analyses of all controlled, randomised dietary trials, in which the only type of intervention was a lowering of dietary saturated fats and an increase of dietary polyunsaturated fats, found that the total number of deaths was identical in the treatment and the control groups. ${ }^{2-5}$

Uffe Ravnskov independent researcher

Magle Stora Kyrkogata 9, 22350 Lund, Sweden ravnskov@tele2.se

Competing interests: None declared.

1 Zatonski WA, Willett W. Changes in dietary fat and declining coronary heart disease in Poland: population based study. BMJ 2005;331:187-8. (23 July.) 
2 Ravnskov U. The questionable role of saturated and polyunsaturated fatty acids in cardiovascular disease. J Clin Epidemiol 1998;51:443-60.

3 Leosdotir M, Nilson PM, Nilssson JÅ, Månsson H, Leosdotir M, Nisson $\mathrm{FM}$, Nilssson $\mathrm{JA}$, Mánsson Peralund mortality patterns- data from the Malmo

4 Hooper L, Summerbell CD, Higgins JPT, Thompson R, Capps NE, Davey Smith G, et al. Dietary fat intake and pre2001.322:757-63

5 Ravnskov U. Diet-heart disease hypothesis is wishful thinking. BMJ 2002;324:238.

\section{HIV risk environment in Hungary is} different from that in Russia and west Balkan states

EDITOR-In Hungary the HIV risk environment is not quite as severe as in Russia and the west Balkans, and the macroenvironmental (especially economic and social) components are not the same. ${ }^{1}$ Hungary did not experience the rapid changes in its population; the collapse of its healthcare and welfare systems; or the precipitous economic, social, and cultural crises that took place in Russia. Hungarian drug policy, which contains elements of harm reduction, will also contribute to preventing the massive spread of infectious diseases. For example, qualitative studies on injecting drug users in Hungary underline the importance of unlimited availability of injecting equipment in pharmacies and the help of needle exchange programmes (which are, however, available only in bigger cities). ${ }^{2}$

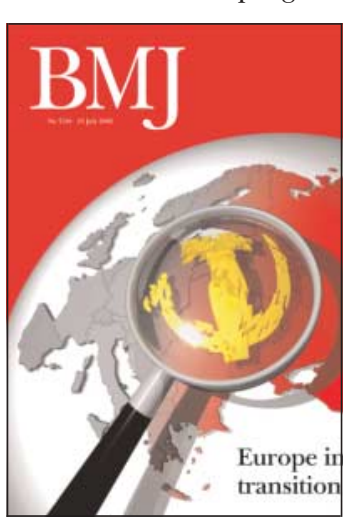

The problems mentioned included the deterioration in health and social services since the collapse of the communist system in eastern Europe. The opportunity to study prospectively what is possibly the biggest system reform in our time was missed because the pressure to deliver changes overnight was so strong that a more systematic, planned, and reasoned approach seemed to equal sabotage. Money was spent on reforms but without monitoring because of this pressure. Consequently, baseline data to measure progress and impact of reform are hardly available, although UNICEF's TransMonee database was mentioned as a resource.

Human resources were also identified as a problem-not because of a lack of trained people but because of attitudinal or financial problems, political conflicts of interest, a lack of practical skills, and a lack of incentives. A lack of money was identified as a hindrance to progress by some, but a lack of knowledge of how to use existing resources most effectively was probably worse. An absence of individuals' responsibility for their health-another problem-may be a legacy of communism. Scarce finances affect preventive health measures, such as screening programmes, which have deteriorated in some parts of eastern Europe. Participants even wondered whether some governments take health problems in their countries seriously and whether years

Although the HIV prevalence is zero among injecting drug users, the prevalence of hepatitis $\mathrm{C}$ is about $30-35 \%$. According to our experience, the HIV testing is widespread, but the opportunities for testing for hepatitis $\mathrm{C}$ virus are limited: either in abstinence oriented drug clinics or low threshold services. Opportunities for testing need to be improved urgently, and the coverage of the low threshold services in connection with injecting drug users needs to be increased. ${ }^{3}$

József Rácz researcher,psychiatrist

Institute for Psychology, Victor Hugo 18-22, Budapest-1132, Hungary

raczj@t-online.hu

Competing interests: None declared.

1 Rhodes T, Simic M. Transition and the HIV risk environment. BMJ 2005;331:220-3. (23 July.)

2 Rácz J. Injecting drug use, risk behaviour and risk environment in Hungary: a qualitative analysis. Int J Drug Policy (in press).

3 Gyarmathy VA, Rácz J, Neaigus A, Ujhelyi E. The urgent need for HIV and hepatitits prevention in drug treatment programs in Hungary. AIDS Educ Prevent 2004;16,3:276-88.

\section{Summary of webchat}

The aim of the theme issue of Europe in transition was to give a snapshot of countries in political and economic transition. Participants in the accompanying webchat discussed problems that they were facing in the course of their own work, analysed where these problems might stem from, and thought of some tentative solutions. ${ }^{1}$ under communist rule might have created an aversion to solving problems collectively

Suggested solutions to this array of problems included capacity building and pan-European health programmes. Providing governments with unbiased international decision support or opportunities to work with international bodies may help because small collaborative pilot projects have already been found to be effective.

Funding and government support were seen as perennial problems, although joint international applications from academic partners were regarded as having a chance of success. Good epidemiological and economic studies could help to provide a common focus. The health agenda needs to be supported at the overall political level, not just by sectoral bodies, and the population and healthcare providers were called on to change their thinking to enable reform, which requires a major change in values and taking responsibility for one's own health. Central and local governments need to collaborate better. Central governments should set standards and monitor progress, while local governments, better informed about local needs and conditions, should set strategies.

How might the $B M J$ help? It could invite contributions from the region, especially from those studying problems across coun- tries, and it could lead training courses on publishing papers there. Perhaps another theme issue on transition economies could be published in a year's time as part of a continuing process of monitoring progress. A similar online discussion for policy makers and another webchat covering one specific public health topic could also be useful.

Birte Twisselmann assistant editor (web)

BMJ

Competing interests: None declared.

Webchat. Europe in transition (28 July 2005). http:// bmj.bmijournals.com/cgi/content/full/331/7510/DC2.

\section{Ignore fairy tales when campaigning for NHS reform}

Editor-I find it hard to see why the Poet Laureate or Philip Pullman has anything useful to say about NHS reform. ${ }^{1}$ However good their writing (and it is), their views of the NHS are mere fairy tales.

The "collaborating network" so threatened by competition doesn't exist. The NHS that I know has good parts, but other parts lose your medical records when you move from unit to unit, fail to eliminate bad medical practice, and have consultants whose rivalry over who gets patients into beds is a serious barrier to running the hospital efficiently.

As for the "planned and equitable" way it delivers care to patients: in the real world, centrally planned economies are a total failure because the incentive to improve is completely dominated by the incentive to be uniform. Competition creates a sufficiently powerful incentive to improve how things are organised that the long term benefit to all is far greater than the apparent inefficiency of competition.

But the most absurd statement of all is the idea that "growth in paperwork" is eating into "scarce funding." How any organisation where spending has doubled in a mere decade could consider funding "scarce" is rich enough. But the idea that all management activity is parasitic on the hardworking medical staff (which is what the jibe about paperwork implies) is another fairy tale. The real NHS isn't like that. It's under-managed and badly organised, and putting good managers in place can often dramatically improve the capacity of the medical staff to treat patients.

The underlying assumption behind the opposition to reform is that the current NHS is as good as it can be and there is no way to do it better. There is legitimate debate about how to do better, but starting with a fairy tale view of how the NHS is now is not a good place to start.

Stephen I Black management consultant London SW1W 9SR stephen.black@paconsulting.com

Competing interests: SIB has worked as a management consultant in the health system.

1 Arie S. Writers join experts to campaign to save NHS from privatisation. BMJ 2005;331:713. (1 October.) 